\title{
Superficial vein Thrombophlebitis
}

\section{Dr. Rasha Magdy Mohamed Said \\ Lecturer of Internal medicine and Hematology Department Ain Shams University}

Superficial thrombophlebitis is a common inflammatory-thrombotic disorder in which a thrombus develops in a vein located near the surface of the skin

(Markovic et al., 1997)

Most superficial veins that develop thrombosis also have phlebitis, in contrast to deep venous thrombosis (DVT), a sometimes asymptomatic condition in which phlebitis may be absent

Although superficial thrombophlebitis usually occurs in the lower extremities (saphenous vein of the leg), it also has been described in the penis and the breast (Mondor disease) (Nazir and Khan.2010)

It can also develop anywhere that medical interventions occur, as in the arm or neck (external jugular vein) when intravenous (IV) catheters are used. (Kagel and Rayan.2004)

Thrombosis of superficial veins has long been regarded as a benign disorder and a selflimiting, however, it can be complicated by deep vein thrombosis (DVT) and even pulmonary embolism (PE).

$65.6 \%$ of patients who presented with great saphenous vein thrombosis were found to have associated DVT (Ascher et al., 2003) .

\section{Pathophysiology}

Vascular endothelial injury as triggering agent result in thrombus formation. This injury initiates an inflammatory response that results in immediate platelet adhesion at the injury site. Further platelet aggregation is mediated by thromboxane A2 (TxA2) and by thrombin. 


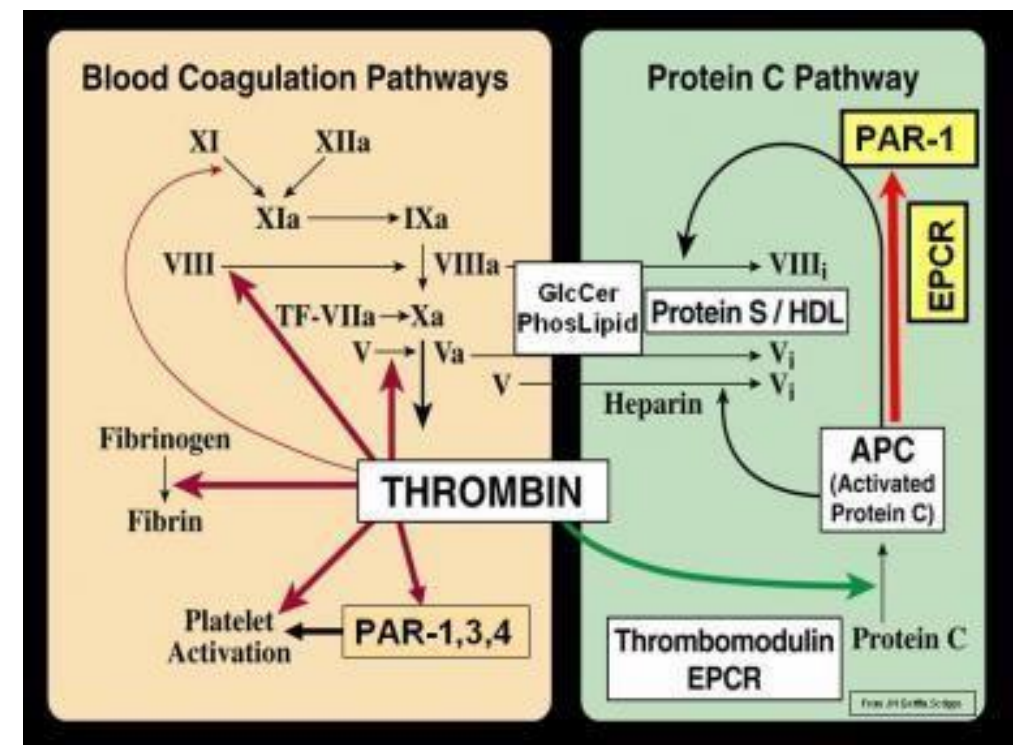

Fig(1)coagulation cascade

Platelet aggregation due to TxA2 is inhibited irreversibly by aspirin and reversibly by other nonsteroidal anti-inflammatory drugs (NSAIDs); thrombin-mediated platelet aggregation, on the other hand, is not affected by NSAIDs, including aspirin.

\section{Contributing Risk factors include,}

Varicose veins, Obesity, Age older than 60 , Cigarette smoking ,IV drug abus, Hypercoagulable states (Franchini et al.,2006)

Defects responsible for hypercoagulability Table(1) 
Activated protein $\mathrm{C}$ resistance (factor $\mathrm{V}$ Leiden)

Protein C deficiency

Antithrombin deficiency

Hyperhomocysteinemia

Prothrombin 20210A allele

Dysplasminogenemia

High plasminogen activator inhibitor

Dysfibrinogenemia

Elevated factor VIII

Antiphospholipid syndrome
Thrombocythemia

Dysproteinemia

Heparin-induced thrombocytopenia

Estrogens

Birth control pills

Hormone replacement therapy

Malignancy

Pregnancy

Bed rest

Surgey .Trauma

\begin{tabular}{|l|l|l|}
\hline Disorder & Gene frequency & $\begin{array}{l}\text { Cause of } \\
\text { hypercoagulability }\end{array}$ \\
\hline & & \\
\hline APC resistance & $3.6 \%-6.0 \%$ & $10 \%-64 \%$ \\
\hline Protein S deficiency & $0.50 \%$ & $1.4 \%-7.5 \%$ \\
\hline Protein C deficiency & $0.33 \%$ & $1.4 \%-8.6 \%$ \\
\hline Antithrombin deficiency & $0.10 \%$ & $0.5 \%-4.9 \%$ \\
\hline Prothrombin 20210A & $0.7 \%-6.0 \%$ & $5.0 \%-7.1 \%$ \\
\hline
\end{tabular}

Table (2) Frequency of Inherited Defects and Hypercoagulability (Ames etal., 1998)

Systemic lupus erythematosus, Acquired immunodeficiency syndrome (AIDS) Lupus anticoagulant, Drug-induced lupus anticoagulant, Behçet disease, Blood type A, hemolytic anemia (Whitlatch and Ortel.2008)

Phlebitis occurs in diseases associated with vasculitis, such as polyarteritis nodosa (periarteritis nodosa) and Buerger disease (thromboangitis obliterans) in which there was phlebitis in $\mathbf{8}$ of 19 patients, and in $\mathbf{4 3} \%$ of the $\mathbf{2 5 5}$ patients of buerger disease. (Shionoya.1990)

Pregnancy, throughout and after 6 weeks of delivery, due to increase in most procoagulant factors and a reduction in fibrinolytic activity occur. Plasma fibrinogen levels gradually increase after the third month of pregnancy, reaching 
double the normal state. In the second half of pregnancy, levels of factors VII, VIII, IX, and X also increase (Pomp et al., 2008)

Also those who carry the factor V Leiden or prothrombin C-20210-a gene, because they already have a predisposition to clotting, which would also be exacerbated by pregnancy.

High-estrogen oral contraceptives, a woman may increase her risk of thrombosis by a factor of 3-12 times, Newer low-dose oral contraceptives are associated with a much lower risk of thrombophlebitis (Rosendaal et al.,2001).

Thrombophlebitis in varicose vein may follow trauma to a varix, or without an antecedent cause. Bleeding may occur as the reaction extends through the vein wall. it is observed in varicose veins surrounding venous stasis ulcers.

Infection-related thrombophlebitis following operations or after injection treatments, trauma, or exposure to radiation therapy (Mermel et al., 2009)

In case of hypercoagulability in association with malignancies, with the classic example being Trousseau syndrome-a thrombotic event occurring prior to an occult malignancy, The pathophysiology of malignancy-related thrombosis is poorly understood, but tissue factor, tumor-associated cysteine proteinase, circulating mucin molecules, and tumor hypoxemia have all been implicated as causative factors (Varki, 2007)

Patient complain of tenderness, induration, pain and/or erythema along the course of a superficial vein usually establish a clinical diagnosis, especially in patients with known risk factors (Fernandez et al., 2010).

On physical examination, the skin over the affected vein exhibits erythema, warmth, swelling, and tenderness. Later in the disease, as induration subsides, erythema gives way to a ruddy or bruised color (Karwowski et al., 2013)



fig (2) superficial thrombophlebitis of the great saphenous vein 
In addition, there is a palpable, sometimes nodular cord, due to thrombus within the affected vein. Persistence of this cord when the extremity is raised suggests the presence of thrombus (Fernandez et al.,2010)

Patient characteristics and predisposing factors for thrombophlebitis nearly mirror those for DVT; thrombophlebitis is a risk factor for the development of DVT, and vice versa.

Lower extremity superficial phlebitis is associated with conditions that increase the risk of thrombosis, including abnormalities of coagulation or fibrinolysis, endothelial dysfunction, infection, venous stasis, intravenous therapy and intravenous drug abuse which are components of virchows triad (Fernandez et al., 2012)

Duplex ultrasound identifies the presence, location and extent of venous thrombosis, also may identify the pathology that may be a source of the patient's complaints.


Fig(3) 


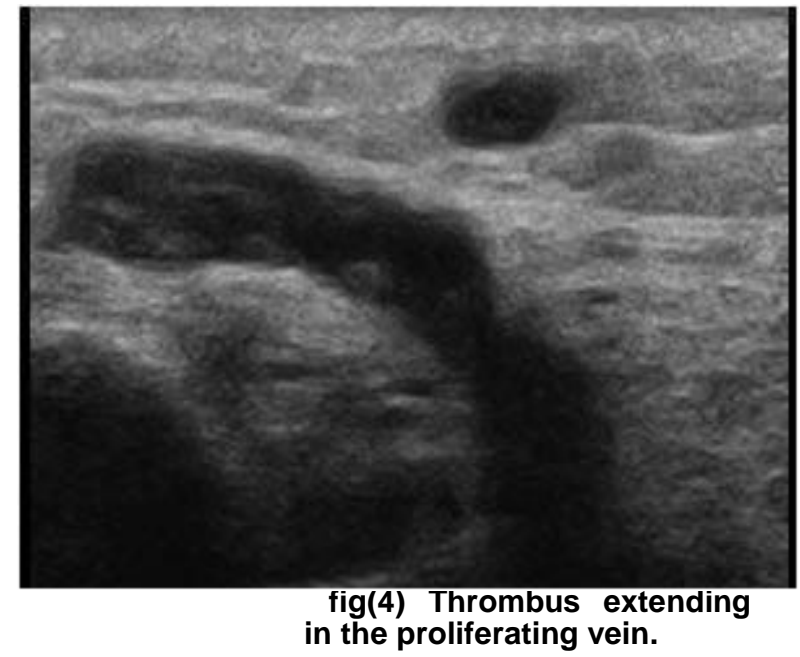

Ultrasound is indicated if superficial phlebitis involves or extends into the proximal onethird of the medial thigh otherwise clinical diagnosis will be enough (Fernandez et al., 2010).

Current treatment options are aimed at resolving symptoms, preventing recurrence and preventing extension to the deep venous system, for potentiality of thromboembolism.

Treatment with compression stockings should be offered to patients with lower extremity superficial phlebitis, if not contraindicated (e.g., peripheral artery disease).

Gradient compression stockings are adjunctive therapy that is both benign and effective. They provide a gradient of compression that is highest at the toes (at least $\mathbf{3 0 - 4 0 ~} \mathrm{mm} \mathrm{Hg}$ ) and gradually decreases to the level of the thigh. Which reduces capacitive venous volume by approximately $\mathbf{7 0 \%}$ and increases the measured velocity of blood flow in the deep veins by a factor of $\mathbf{5}$ or more.

Gradient compression hose also have been shown to increase local and regional intrinsic fibrinolytic activity. Patients may find them helpful for reducing swelling and pain once the acute inflammation subsides.

Non-steroidal anti-inflammatory drugs (NSAID) are effective in relieving the pain associated with venous inflammation and were found in a randomized trial to significantly decrease extension and/or the recurrence of superficial vein thrombosis. (Arch Intern Med. 2003) 
Also (NSAIDs) and low-molecular-weight heparin (LMWH) are known to be the first options (Di Nisio et al., 2007)

Anticoagulation for patients with lower extremity superficial thrombophlebitis at increased risk for thromboembolism (affected venous segment of $\geq 5 \mathrm{~cm}$, in proximity to deep venous system, positive medical risk factors (Kearon et al., 2008)

Treatment with fondaparinux (inhibitor factor $\mathrm{X}$, long acting, once daily) reduces the risk of subsequent venous thromboembolism (Di Nisio et al., 2012)

Also when compared with placebo fondaparinux found to be a good option in those patients as regard rate of recurrence and reducing symptoms and extension of SVT. (Di Nisio et al., 2013)

In a small, randomized trial of 60 patients with great saphenous vein thrombosis, Lozano et al compared treatment using LMWH with surgical saphenous ligation, Patients in the LMWH group experienced no episodes of DVT or PE but had a $10 \%$ incidence of recurrent superficial venous thrombosis.

Among the patients treated surgically, two pulmonary emboli $(6.7 \%)$ were found, and one episode of recurrent superficial venous thrombosis (3.3\%) occurred (Lozano et al., 2003)

Surgical intervention is reserved for extension of the clot to within $1 \mathrm{~cm}$ of the saphenofemoral junction or in patients unfit for anticoagulation, or failure of anticoagulation and patients with intense pain (Karwowski et al., 2013)

Surgical therapy with ligation of saphenofemoral junction or stripping of thrombosed superficial veins appears to be associated higher rates of venous thromboembolism compared with treatment with anticoagulants (Belcaro et al., 1999)

The thrombophlebitic vein may be excised in Patients who demonstrate signs and symptoms of septic thrombophlebitis require urgent venous excision to control the septic focus with removal of the infected thrombosed vein (Quenet et al., 2003).

Complications recorded include superficial vein thrombosis extension to the deep vein system and/or recurrence of SVT.

Supportive thrombophlebitis is suspected when erythema extends significantly beyond the margin of the vein and is associated with significant fever. If 
suspected, antibiotic treatment, surgical drainage and potentially vein excision are indicated (Davidovic et al., 1990)

Venous thromboembolism can occur with superficial vein thrombosis. Estimates of the percentage of patients with SVT who also have DVT vary between $6 \%$ and $53 \%$, and symptomatic pulmonary embolism has been reported in $0 \%$ to $10 \%$ of patients with SVT. (Decousus et al., 2010)

\section{References}

Ann Intern Med 2010; 152:218 / Superficial venous thrombosis and venous thromboembolism: a large, prospective epidemiologic study /

Ames PR, Tommasino C, D'Andrea G, et al: Thrombophilic genotypes in subjects with idiopathic antiphospholipid antibodies -- prevalence and significance. Thromb Haemost 1998; 79:46-49

Ascher E, Hanson JN, Salles-Cunha S, et al. Lesser saphenous vein thrombophlebitis: its natural history and implications for management. Vasc Endovascular Surg. 2003 Nov-Dec. 37(6):421-7.

Belcaro G., et al./Superficial thrombophlebitis of the legs: a randomized, controlled, follow-up study/Angiology 1999;50:523

Davidovic L., et al./Indications for surgical treatment of acute superficial thrombophlebitis/Srp Arh Celok 1990;118:471

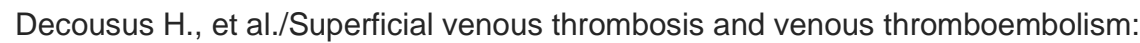
a large, prospective epidemiologic study/Ann Intern Med. 2010;152(4):218-224

Di Nisio M, Wichers IM, Middeldorp S. Treatment for superficial thrombophlebitis of the leg. Cochrane Database Syst Rev. 2007 Apr 18. CD004982

Di Nisio, M; Wichers, IM; Middeldorp, S (Mar 14, 2012). "Treatment for superficial thrombophlebitis of the leg.". Cochrane database of systematic reviews (Online) 3: CD004982.

Di Nisio M, Wichers IM, Middeldorp S. Treatment for superficial thrombophlebitis of the leg. Cochrane Database Syst Rev. 2013 Apr 30. 4:CD0049 
Fernandez, L., et al. / Superficial thrombophlebitis of the lower extremity / uptodate.com 2010

Fernandez, L., et al. / Superficial thrombophlebitis of the lower extremity / uptodate.com 2012

Franchini M, Veneri D, Salvagno GL, Manzato F, Lippi G. Inherited thrombophilia. Clin Lab Sci. 2006. 43:249-90.

Kagel EM, Rayan GM. Intravenous catheter complications in the hand and forearm. J Trauma. 2004 Jan. 56(1):123-7.

Karwowski, J., et al. / How to manage thrombophlebitis of the lower extremities / $\mathrm{J}$ of Fam Prac 2013:554-558

Kearon C., et al./Antithrombotic therapy for venous thromboembolic disease: American College of Chest Physicians Evidence-Based Clinical Practice Guidelines (8th Edition)/Chest 2008;133:454S

Lozano FS, Almazan A. Low molecular weight heparin versus saphenofemoral disconnection for the treatment of above knee greater saphenous thrombophlebitis: a prospective study. Vasc Endovascular Surg. 2003. 37:41520.

Markovic MD, Lotina SI, Davidovic LB, et al. [Acute superficial thrombophlebitis-modern diagnosis and therapy]. Srp Arh Celok Lek. 1997 Sep-Oct. 125(910):261-6.

Mermel LA, Allon M, Bouza E, et al. Clinical practice guidelines for the diagnosis and management of intravascular catheter-related infection: 2009 Update by the Infectious Diseases Society of America. Clin Infect Dis. 2009 Jul 1. 49(1):1-45.

Nazir SS, Khan M. Thrombosis of the dorsal vein of the penis (Mondor's Disease): A case report and review of the literature. Indian J Urol. 2010 Jul. 26(3):431-3.

Pomp ER, Lenselink AM, Rosendaal FR, Doggen CJM. Pregnancy, the postpartum period and postthrombotic defects: risk of venous thrombosis in the MEGA study. J Thromb Haemost. 2008. 6:632-637.

Quenet S, Laporte S, Décousus H, et al. Factors predictive of venous thrombotic complications in patients with isolated superficial vein thrombosis. J Vasc Surg. 2003 Nov. 38(5):944-9. 
Rosendaal FR, Helmerhorst FM, Vandenbroucke JP. Oral contraceptives, hormone replacement therapy and thrombosis. Thromb Haemost. $2001 \mathrm{Jul}$. 86(1):112-23 .

Shionoya S. Buerger's Disease: Pathology, Diagnosis and Treatment. Nagoya, Japan: University of Nagoya Press; 1990.

Superficial Thrombophlebitis Treated By Enoxaparin Study Group/A pilot randomized double-blind comparison of a low-molecular-weight heparin, a nonsteroidal anti-inflammatory agent, and placebo in the treatment of superficial vein thrombosis./Arch Intern Med. 2003;163(14):1657.

Varki A. Trousseau's syndrome: multiple definitions and multiple mechanisms. Blood. 2007. 110:1723-1729.

Whitlatch NL, Ortel TL. Thrombophilias: when should we test and how does it help. Semin Respir Crit Care Med. 2008. 29:25-39.



